\title{
EDITORIAL
}

\section{Communicable Disease Control}

The Public Health movement originates from the last century and the need to combat the sanitary and environmental nightmares of Victorian Britain. John Snow's removal of the Broad Street water pump handle symbolised the sudden understanding of the epidemiology of the London Cholera Epidemic of 1849. Eventually the Public Health Act of 1897 made the notification to the local authority of cases of cholera, plague, smallpox, tetanus and rabies a statutory requirement of doctors. This requirement was enshrined in primary legislation and extended to include food poisoning at a later date. Over the years additional regulations and secondary legislation have added a further 24 infectious diseases to the statute book. In England and Wales the most up-to-date legislation is the 1984 Public Health Act. Both Scotland and Northern Ireland, with their separate legal systems and public health traditions, have their own legislation which is essentially similar to the English form but there are one or two differences in their lists of notifiable diseases.

Notification is made to the local authority and its duly appointed Proper Officer. This arrangement worked well when there was a Medical Officer of Health (MOH) for each local authority, ably assisted by his Sanitary Inspectors, but the local government and health service reorganizations of 1974 brought about a dichotomy in responsibility. This was due to the fact that the $\mathrm{MOH}$ became a member of the newly formed health authority and the Sanitary or Public Health Inspectors, now renamed Environmental Health Officers (EHO), remained with local government. In order to provide for the extant responsibilities of legislation, local authorities appointed a community health physician from the health authority, known as the Medical Officer of Environmental Health (MOEH), to act as the Proper Officer. There were some authorities who appointed their Chief EHO as MOEH. The problem was that most MOEHs spent only a small proportion of their time dealing with infectious disease.

Events came to a head in the mid-eighties when some major infectious disease outbreaks were inadequately investigated and controlled. In 1988 an Enquiry chaired by the then Chief Medical Officer at the Department of Health, Sir Donald Acheson, reported on the speciality and function of Community Medicine, itself born of the 1974 reorganization. That wide ranging report on the State of the Public Health in England strongly recommended a return to the public health imperatives of yore and the renaming of community medicine as public health medicine. The report recommended changes in the conduct of disease reporting, investigation and control, and in particular recommended the appointment of a Consultant in Communicable Disease Control (CCDC) to every district and to replace eventually all the MOEHs.
In October 1991 the Department of Health (DoH)O issued a circular to all regions and districts which gavec guidance as to the conduct of communicable disease control. The essential message was about collaboration $\stackrel{\vec{S}}{\vec{s}}$ between health authorities and local authorities, ap-o pointment of a CCDC and outbreak control planning, 흠 and an invite to submit regional and district plans by $\frac{\bar{s}}{\vec{b}}$ May 1992.

At the same time there were two infectious disease outbreaks in Army establishments in UK which suffered ${ }_{\vec{O}}$ from problems in liaison with the local civilian bodies, $:$ notably the CCDC and the Public Health Laboratory $\vec{\omega}$ Service, and reporting procedures. In consequence the $\mathrm{O}$ Director of Health deemed it appropriate that a TriService review, taking into account the DoH circular, should take place. Based on the experience of the RAF, who had a well established Communicable Disease Ad- $\omega$ visory Team (CDAT), Single Service and DoH staffing, a Joint Service Policy Letter on Communicable Disease Control was promulgated in June 1992. The principal areas covered in the policy letter were the notification 9 and surveillance of infectious disease, the investigation and management of outbreaks of infectious disease, the role of a Service CCDC, the role of a CDAT and liaisक्षn with civilian bodies.

All medical officers, making the diagnosis of $\frac{\sigma}{6}$ notifiable disease, were reminded of their legal obliggtion to notify the Proper Officer and appropriate Servige parties, in particular the new Single Service CCDC, wi best speed. It was an appropriate moment to revamp the Service notification form, the F Med 85 , which now includes all the notifiable diseases on each sheet and an\% updated guide on the obverse as to distribution. $\mathrm{A} \stackrel{\mathrm{Q}}{\mathrm{Q}}$ working definition of food poisoning was included in the $\overrightarrow{\vec{O}}$ policy letter to aid diagnosis and notification. Sur- 3 veillance was to be improved by the Single Service CCDC producing a quarterly summary return, based on the $F_{-}$ Med $85 \mathrm{~s}$, for the Director of Health. In addition the 3 CCDC was encouraged to provide a quarterly newsletter for hospitals and primary care which might provide useful feedback to reporting medical officers.

Each Service has now appointed their own CCDC. Typical terms of reference for him include taking the lead in communicable disease control through the 3 . CDAT, providing advice to medical staff, medical offi-i cers and Service hospitals, liaison with the Communica-3 ble Disease Surveillance Centre, civilian CCDCs and laboratories, calling together outbreak control committees and reviewing Service outbreak control plans. For good practical Service reasons it was decided that $a$ microbiologist was the most appropriate candidate for $N$ appointment as CCDC and that is exactly what the Armyn has done by appointing the microbiologist at QueenN Elizabeth Military Hospital (QEMH). 
However the CCDC cannot do it all on his own and so an Army CDAT has been formed which also includes a public health physician: the SO1 Prev Med at HQ UKLF, and an EHO: the OC EH Div at the RAMC Training Centre. The duties of the CDAT are seen as investigation of an outbreak and thus normally forming the core of an outbreak control committee, advice on prevention and control of communicable disease, and compiling reports on outbreaks.

Communicable disease has killed more servicemen than shell or shot has ever managed. Our future military challenges will take us to parts of the world where the environment is hostile and infectious diseases are prevalent. There is a perception that in some parts of the world there may be an emerging threat from biological warfare, it may therefore be difficult, in certain situa- tions, to distinquish between naturally occurring disease and weapon delivered disease. Although our preventive $\vec{z}$ medicine was a resounding success in the recent Gulf $\propto$ War our surveillance was poor. The foundations for $\Omega$ effective surveillance and maintaining low levels of morbidity in war are laid in peace. Thus we must get right now the new and reorganized systems put in place. $\vec{F}$ To discover the success of these, medical officers are being surveyed as to their knowledge of communicable disease and the reporting system. It may be salutory to $\frac{\bar{\omega}}{\mathrm{N}}$ discover the success or otherwise of the medical chain of $\mathbb{\nabla}$. command in disseminating to medical officers these arrangements and in inculcating a philosophy of compli- $\omega$. ance in peace for translation into the field during war.

A H M MaCMILLAN

\section{ACADEMIC ACHIEVEMENTS}

FRCPath

MRCP

FRC Anaes

MSc (Immunology for Disease Control)
Colonel R C Menzies, L/RAMC

Captain P A Haynes, RAMC

Major K J Heath, RAMC

Lieutenant K A Smith, RAMC 